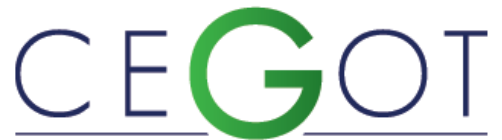

Centro de Estudos de Geografia e Ordenamento do Território
Geografia e Ordenamento do Território, Revista Eletrónica Centro de Estudos de Geografia e Ordenamento do Território http://cegot.org

SOUZA, JAIRO

Universidade do Vale do Paraíba, Instituto de Pesquisa e Desenvolvimento, Programa de Pós-Graduação em

Planeamento Urbano e Regional

Avenida Comendador Vicente de Paulo Penido, 532, Jardim Aquarius, São

José dos Campos, São Paulo, Brasil, CEP: 12246-856

issouza@defensoria.sp.def.br

\author{
RESCHILIAN, PAULO \\ Universidade do Vale do Paraíba, Instituto de Pesquisa e \\ Desenvolvimento, Programa de Pós-Graduação em \\ Planeamento Urbano e Regional \\ 12.244-000, São José dos Campos, Brasil \\ pauloromano@univap.br
}

\title{
Reforma da estrutura orgânica dos municípios e institucionalização das representações sociais sobre a cidade: a primazia da gestão gerando uma (des)ordem urbana em São José dos Campos, Brasil
}

Reform of the administrative structure of municipalities and the institutionalization of social representations about the city: the primacy of management generating an urban (dis)order in São José dos Campos, Brazil

Referência: Souza, Jairo; Reschilian, Paulo (2018). Reforma da estrutura orgânica dos municípios e institucionalização das representações sociais sobre a cidade: a primazia da gestão gerando uma (des)ordem urbana em São José dos Campos, Brasil. Revista de Geografia e Ordenamento do Território (GOT), n. 15 (dezembro). Centro de Estudos de Geografia e Ordenamento do Território, p. 403-428, dx.doi.org/10.17127/got/2018.15.017

\section{RESUMO}

Este artigo procura desvelar os mecanismos de adaptação legislativa utilizados no Município de São José dos Campos, Brasil, para instituicionalização de uma representação social construída a partir de um discurso de respeito às regras e de fomento ao empreendedorismo, na tentativa de qualificar o local para competir por novos capitais. Pretende-se debater o potencial de produção da ordem urbana para cumprir tal fim, a partir da inversão do processo que constrói uma racionalidade do Planeamento e do rearranjo dos fluxos de tomada de decisões, engendrados pela alteração da estrutura orgânica, implementada no início do ano de 2017, que apontam para o fortalecimento do poder tecnocrático e o consequente esvaziamento da política. Conclui-se enfatizando a necessidade de mudança de paradigma com primazia do Planeamento urbano democrático e do Direito à Cidade.

Palavras-chave: Planeamento urbano, representações sociais, ordem urbana, São José dos Campos, Direito à Cidade

\section{ABSTRACT}

This article intends to unveil the mechanisms of legislative adaptation used in São José dos Campos, Brazil, for the institutionalization of a social representation constructed from a discourse of respect to the rules and of foment to the entrepreneurship in an attempt to 
qualify the place to compete for new capital. Discusses the potential of production of urban order by reversing the logical process of planning and rearrangement of the decision-making flows engendered by changing the administrative structure implemented at the beginning of 2017, which point to the strengthening of technocratic power and the consequent emptying of politics. It concludes by emphasizing the need for a paradigm shift based on the primacy of democratic urban planning and the Right to the City.

Keywords: urban planning, social representations, urban order, São José dos Campos, social representations, right to the city

\section{Introdução}

A ideia da neutralidade das denominadas normas de organização (BARROSO,2003:109), também denominadas de normas estruturais (BOBBIO, 1997:45), há muito está superada no debate jurídico.

Dentro da clássica dicotomia "normas de conduta" e "normas de organização", atribuía-se um valor secundário às normas que estruturavam as organizações e regulavam a própria produção do direito que, segundo parte dos teóricos positivistas, não repercutiriam de forma decisiva na regulação da conduta humana.

Para HERRERA-FLORES (2000:27), os seres humanos não precisam de direitos, mas de vida digna, ou seja, da satisfação de suas necessidades. Com efeito, o estudo do Direito deve ser crítico, revelando as escolhas efetuadas, os conflitos de interesses que se escondem atrás de todo debate permeado de ideologia, inserindo-o nos contextos sociais, culturais e políticos e desvelando os mecanismos intelectuais e as estratégias utilizadas para negar a verdade.

Assim, o direito seria sempre um processo dinâmico de confrontação de interesses, nunca o resultado neutro de uma decisão arbitrária do poder (Id., p.31).

Em sentido similar BOURDIEU (1989: 243-244) assinala que o direito: "forma por excelência do discurso legítimo (...), só pode exercer sua eficácia específica na medida em que obtém o reconhecimento, quer dizer, na medida em que permanece desconhecida a parte maior ou menor de arbitrário que está na origem de seu funcionamento. A crença que é tacitamente concedida à ordem jurídica deve ser reproduzida sem interrupção e uma das funções do 
trabalho propriamente jurídico de codificação das representações e das práticas éticas é a de contribuir para fundamentar a adesão dos profanos aos próprios fundamentos da ideologia profissional do corpo dos juristas, a saber, a crença na neutralidade e na autonomia do direito e dos juristas".

Em verdade, é de se constatar que não importa a taxionomia ou natureza das normas: a autoridade jurídica, forma de violência simbólica legítima, com monopólio estatal, jamais será neutra (BOURDIEU, 1989:211).

O descompasso entre uma estrutura jurídica projetada e as funções atribuídas a essa estrutura pode inviabilizar a realização dos objetivos enunciados pela norma, tornando inconsistente qualquer argumentação sobre o caráter neutro das normas de organização.

Segundo BOBBIO (1998:11), "as estruturas administrativas representam, mais do que tudo, o traço característico dos Estados modernos e contemporâneos, manifestando, quase fisicamente, sua presença no plano subjetivo".

Assim, afeiçoa-se relevante a análise do desenho normativo-institucional de uma determinada organização para revelar a aptidão dessa estrutura para cumprimento das funções que enuncia.

No campo do Planeamento Urbano, a tônica da abordagem jurídica, na escala local, centrase, em grande medida, na análise de Planos Diretores, Leis Urbanísticas (Zoneamento, uso e ocupação do solo, códigos de obras etc.), programas, projetos e ações específicos.

O presente estudo propõe a alteração do foco de aproximação, para demonstrar como a regulamentação e reordenação da estrutura orgânica local pode materializar os "princípios ideológicos e os esquemas mentais de um determinado grupo social hegemônico" (WOLKMER,1989:121).

Por efeito, a análise da evolução dos arranjos e rearranjos normativos da estrutura orgânica do município, na área do Planeamento Urbano, pode contribuir para revelar os mecanismos de institucionalização das representações sociais.

Assim, o presente artigo é dividido em quatro partes, além da introdução e da conclusão.

Parte-se de uma breve revisão das reformas da estrutura orgânica ocorridas no Município de São José dos Campos, a partir da década de 1970, período em que se intensificou o 
processo de urbanização local (COSTA,2007:12), destacando-se as modificações ocorridas na estrutura e no funcionamento dos órgãos ligados à área do planeamento urbano.

Em sequência, discute-se as alterações implementadas pela Lei Municipal no 9.495/2017, que promoveu a reforma da estrutura de governo do Município, com ênfase nas alterações que repercutiram no campo do Planeamento Urbano.

Na terceira parte, põe-se em evidência os processos de construção de representações sociais do ideário da "cidade das regras" e "empreendedora", relacionando-os com as modificações legislativas implementadas pela restruturação da estrutura orgânica operada pela Lei $n$ ㅇ 9.495/2017.

Na quarta parte do texto, aborda-se o processo de geração um arranjo a partir da imposição da nova ordem, evidenciando-se como a alteração legislativa tende a viabilizar a efetivação das três analogias suscitadas por VAINER (2002) (cidade-empresa, cidade-mercadoria e cidade-pátria), e o impacto das pressões globalizantes na escala local.

Em conclusão, refuta-se a neutralidade da produção jurídica, acentuando-se o papel do Direito como potencial modelador da realidade e a necessidade de mudança de paradigma para a construção de uma "cidade de princípios" e solidária.

O método utilizado no desenvolvimento do trabalho consistiu, basicamente, em pesquisa bibliográfica, pesquisa e análise dos atos legislativos e manifestações públicas das autoridades envolvidas na formulação das políticas relacionadas ao Planeamento Urbano, tendo como fontes a legislação municipal e documentos administrativos publicados no Boletim do Município e em sítios eletrônicos, além de matérias jornalísticas.

\section{A Estrutura e a função: a organização administrativa e o Planeamento urbano em São José dos Campos (1970 a 2017)}

No período compreendido entre os anos de 1970 e 2017, o município de São José dos Campos passou por nove reformas na sua estrutura orgânica, que determinaram variados tipos de arranjos da estrutura institucional do Planeamento urbano. 
No início desse período, que coincide com o auge do recrudescimento do regime militar implantado no Brasil, em 1964, observa-se um protagonismo do Planeamento no discurso legislativo municipal (Leis municipais no $1.533 / 70,1.534 / 70$ e 1.537/70), chegando a ser alçado ao status de "Princípio Norteador da Ação Administrativa" (SÃO JOSÉ DOS CAMPOS, 1970c).

No contexto nacional, cabe ressaltar, que após 1964, associado à criação do Banco Nacional de Habitação vincula-se o Serviço Federal de Habitação e Urbanismo (SERFHAU), extinto em 1975, cuja proposta era a de definir o marco regulatório e financiar a elaboração dos Planos Diretores municipais com os recursos do próprio banco, por meio de um Fundo de Financiamento ao Planeamento. A despeito de não lograr pleno êxito nessa perspetiva, a criação do SERFHAU foi um marco na tentativa de balizar a política urbana/habitacional no período e influenciou as municipalidades em suas possibilidades e limites de Planeamento e ação.

A partir de 1976, com a promulgação da Lei no 1.788/76, houve um significativo retrocesso no papel do Planeamento Urbano na estrutura municipal. Já não há mais menção expressa ao território, nem ao plano diretor no rol de documentos básicos, ambos presentes na legislação anterior.

Introduz-se a prevalência dos "princípios técnicos" e da discricionariedade na definição de objetivos, organizando a estrutura dos órgãos administrativos numa lógica técnicoautoritária de Planeamento.

O Plano Diretor de Desenvolvimento Integrado cede lugar ao Plano de Ação de Governo, os instrumentos básicos transformam-se, na nova redação, em "documentos básicos", num prenúncio da implantação dos denominados "planos-discursos", que tende a "esconder a direção tomada pelas obras e pelos investimentos que obedecem a um plano não explícito" (MARICATO, 1997).

De acordo com o discurso contido nesse diploma legislativo, o eixo central do processo de Planeamento desloca-se para o "Plano de Governo", projetando uma atividade planejadora subordinada aos interesses dos detentores ocasionais do poder.

Na década de 1980, a Lei no 3.155/86 operou uma mudança de foco na abordagem do Planeamento municipal, agora com a estrutura voltada para a elaboração de projetos 
urbanísticos, com ênfase na gestão e no avanço do Urbanismo. Este modelo viria a ser reproduzido nas legislações posteriores, com algumas modificações e refinamentos.

No início da década de 1990, foi promulgada a Lei no 3.939/91, ainda em vigor no município, mas que sofreu dezenas de alterações, desde então, com destaque para as promovidas pelas Leis $n \div 06.808 / 05$ e no 6.880/05, que modificaram a estrutura orgânica da Secretaria de Planeamento e Meio Ambiente, desmembrando-a e criando a "Secretaria de Planeamento Urbano", ocasião em que foi modificado o status da "Divisão de Projetos Urbanísticos" para equipará-la, hierarquicamente, com o "Departamento de Planeamento Urbano".

Com a mudança, a estrutura organizacional da Secretaria de Planeamento Urbano passou a contar com dois departamentos: o Departamento de Planeamento Urbano e o Departamento de Projetos Urbanísticos.

Outra alteração relevante promovida na Lei no 3.939/91 foi implementada pela Lei no 7.823 , de 03/04/2009, que reestruturou o gabinete do prefeito, criando uma Assessoria de Projetos Estratégicos.

No mesmo dispositivo da Lei no 7.823/09, foi criada uma Assessoria de Planeamento e Informações, subordinada à Assessoria de Projetos Estratégicos. Em outros termos, no núcleo do poder, o Planeamento passou a ser subordinado aos projetos estratégicos.

A alteração legislativa operada pela Lei no 7.823/09 sinaliza uma clara subordinação do Planeamento aos "projetos estratégicos", projeção linguístico-normativa da concepção neoliberal do Planeamento estratégico-empresarial, voltado aos "planos do mercado" e não mais aos "planos do governo" como era expressamente exaltado na Lei 1.788/76.

O Quadro 1 mostra a evolução da designação dos órgãos responsáveis pelo Planeamento no município, desde a década de 1970, e a trajetória de decadência do Planeamento na estrutura organizacional do ente federativo. 


\begin{tabular}{|c|c|c|}
\hline Data & Norma & Denominação dos órgãos responsáveis pelo Planeamento \\
\hline $06 / 01 / 1970$ & Lei $n$ o $1.533 / 70$ & Assessoria de Coordenação e Planeamento Municipal \\
\hline 03/03/1970 & Lei $n \cong 1.537 / 70$ & Assessoria de Planeamento \\
\hline 23/04/1976 & Lei no 1788/76 & $\begin{array}{c}\text { Coordenadoria Geral de Planos e Programas } \\
\text { Departamento de Planeamento }\end{array}$ \\
\hline $22 / 03 / 1979$ & Lei $n \circ 2.151 / 79$ & Assessoria de Planeamento e Coordenação \\
\hline 19/09/1980 & Lei no 2325/80 & $\begin{array}{l}\text { Assessoria de Planeamento e Coordenação } \\
\text { Secretaria de Planeamento e Informática }\end{array}$ \\
\hline $30 / 07 / 1986$ & Lei $n \circ 3.155 / 86$ & Secretaria de Planeamento Territorial e Urbanismo \\
\hline $21 / 03 / 1991$ & Lei $n \circ$ 3.939/91 & Secretaria de Planeamento e Meio Ambiente \\
\hline $25 / 05 / 2005$ & Lei $n \cong 6808 / 05$ & Secretaria de Planeamento \\
\hline $20 / 09 / 2005$ & Lei no 6880/05 & Secretaria de Planeamento Urbano \\
\hline 03/04/2009 & Lei $n \cong 7.823 / 09$ & $\begin{array}{l}\text { Secretaria de Planeamento Urbano } \\
\text { Assessoria de Projetos Estratégicos }\end{array}$ \\
\hline $24 / 03 / 2017$ & Lei $n \circ 9.495 / 17$ & $\begin{array}{l}\text { Secretaria de Urbanismo e Sustentabilidade } \\
\text { Assessoria de Assuntos Estratégicos e Avaliação }\end{array}$ \\
\hline
\end{tabular}

Quadro 1- Evolução da nomenclatura dos órgãos de Planeamento em São José dos Campos no período de 1970 a 2017

Fonte: https://leismunicipais.com.br/camara/sp/sao-jose-dos-campos

A Lei no 3.939/91 foi alterada significativamente pela Lei n 9.495, de 24 de março de 2017, norma objeto de análise mais detalhada adiante.

\section{O rearranjo da estrutura orgânica implementado pela Lei}

\section{Municipal no 9.495/2017}

Apresentada sob o signo da modernidade e eficiência, a reorganização da estrutura orgânica do município de São josé dos Campos, implementada pela Lei Municipal no 9.495, de 24 de março de 2017, promoveu a aglutinação de funções administrativas, concentrando, em linhas gerais, atribuições já existentes em um número menor de órgãos.

Por efeito, aglutinou as Secretarias de "Planeamento Urbano" e "Meio Ambiente"; o "Departamento de Posturas" da "Secretaria Especial de Defesa do Cidadão"; o "Departamento de Obras Particulares da Secretaria de Obras" e a "Sala do Empreendedor da Secretaria das Relações do Trabalho (SÃO JOSÉ DOS CAMPOS, 2017), formando uma nova secretaria que passou a ser denominada de "Urbanismo e Sustentabilidade".

Neste passo, merece destaque a inserção, na estrutura do órgão responsável pelo Planeamento urbano, da "Sala do Empreendedor", materializando o discurso do 
empreendedorismo, ao entrelaçar Urbanismo com a atividade empresarial, num mesmo órgão.

A justificativa pública oferecida pelo Executivo para a reestruturação orgânica teve como eixo central a necessidade de redução de gastos e o equilíbrio das contas públicas, retomando a retórica neoliberal, adotada como receituário para países do Terceiro Mundo desde a década de 1990: "A proposta de alteração se deve à necessidade de modernizar e simplificar as atividades e rotinas da Prefeitura, desburocratizar a tramitação dos procedimentos administrativos e, principalmente, adequar a estrutura à realidade financeira do Município.

A reorganização prioriza a redução das despesas do Município, através da diminuição do número de cargos comissionados e unificação de Secretarias, compartilhando recursos humanos e materiais, trazendo equilíbrio às contas públicas, sem prejuízo da eficiência no atendimento à população. Importante ressaltar que, com essa unificação, os cargos e setores serão readequados às novas configurações" (SÃO JOSÉ DOS CAMPOS, 2017).

No campo do Planeamento Urbano, objeto de interesse do presente estudo, observa-se que a reforma implementada pela Lei no 9.495/17 promoveu significativas alterações no desenho normativo-institucional da Prefeitura Municipal.

A primeira constatação que pode ser feita é o desaparecimento do termo "Planeamento" dos órgãos que passam a integrar o primeiro escalão da administração municipal.

Apesar dos termos "Planeamento/planejar" aparecerem 120 vezes no texto da Lei no 9.495/17, a maior parte das menções à atividade planejadora encontra-se nos órgãos de nível operacional, de baixa hierarquia funcional e com atribuições de mera gestão de ações específicas.

A exceção é a Assessoria de Assuntos Estratégicos, órgão de assessoria direta ao Chefe do Executivo cujas atribuições são delimitadas pelo artigo 12 da Lei: “Art. 12 À Assessoria de Assuntos Estratégicos e Avaliação compete assessorar o Chefe do Executivo, coordenar os trabalhos de concepção e Planeamento dos projetos estratégicos selecionados, analisar as propostas de novos projetos estratégicos; realizar avaliações periódicas e final dos projetos atinentes à Assessoria (...)" (SÃO JOSÉ DOS CAMPOS, 2017). 
Como se pode observar, a atividade planejadora do órgão cinge-se ao Planeamento de "projetos estratégicos selecionados".

Nos termos da Lei no 9.495/17, o Planeamento Urbano foi inserido nas atribuições da Secretaria de Urbanismo e Sustentabilidade cujas funções são assim delimitadas:

“Art. 29. À Secretaria de Urbanismo e Sustentabilidade compete estudar, planejar, supervisionar, desenvolver, implantar e avaliar planos, programas e projetos de Planeamento territorial urbano e rural do Município; coordenar a fiscalização de obras, posturas e ambiental; e controlar o patrimônio imobiliário e Sala do Empreendedor" (SÃO JOSÉ DOS CAMPOS, 2017).

A confusão conceitual entre Urbanismo e Planeamento Urbano, e a implicação prática da adoção de uma ou de outra concepção, são destacadas por ULTRAMARI (2009: 178-180): "Se urbanismo e Planeamento urbano se preocupam com os fenômenos que moldam a cidade, ampliando-a, evidentemente, para espaços regionais e macrorregionais, eles diferem com mais evidência pela forma como atuam. Enquanto o urbanismo permanece menos multidisciplinar e historicamente preocupado com o desenho que a cidade pode assumir, pela ocupação e uso enganosamente homogêneo dos agentes urbanos, o Planeamento urbano se preocupa com os conflitos os quais esse uso e essa ocupação, obrigatoriamente, geram sobre o espaço da cidade.[...] De um lado, o urbanismo, adotado como instrumento da ação estratégica e de resultados visíveis em curto espaço de tempo; de outro, o Planeamento urbano se prestando àqueles que acreditam na transformação estrutural da sociedade. Na equidistância dessas posturas profissionais, um fértil campo de atuação abandonado. Todavia, a conjuntura atual de opção neoliberal não contribui para essa conjunção. Se o papel do Estado é reduzido e se o interesse do capital é valorizado, o urbanismo, com seu perfil mais monodisciplinar, é valorizado por crer que, pragmaticamente, pode corrigir erros e construir uma cidade melhor e, idealmente, mais competitiva".

A priorização do Urbanismo sobre o Planeamento Urbano, na concepção adotada pela Lei no 9.495/2017, não se limitou à nomenclatura das instâncias, houve um aprofundamento da inversão hierárquica na estrutura do órgão responsável pelo Planeamento Urbano, que fora iniciada com a edição das Leis nํ 6.808/05 e no 6.880/05. 
As figuras 1 a 3 demonstram a evolução do processo de inversão hierárquica.

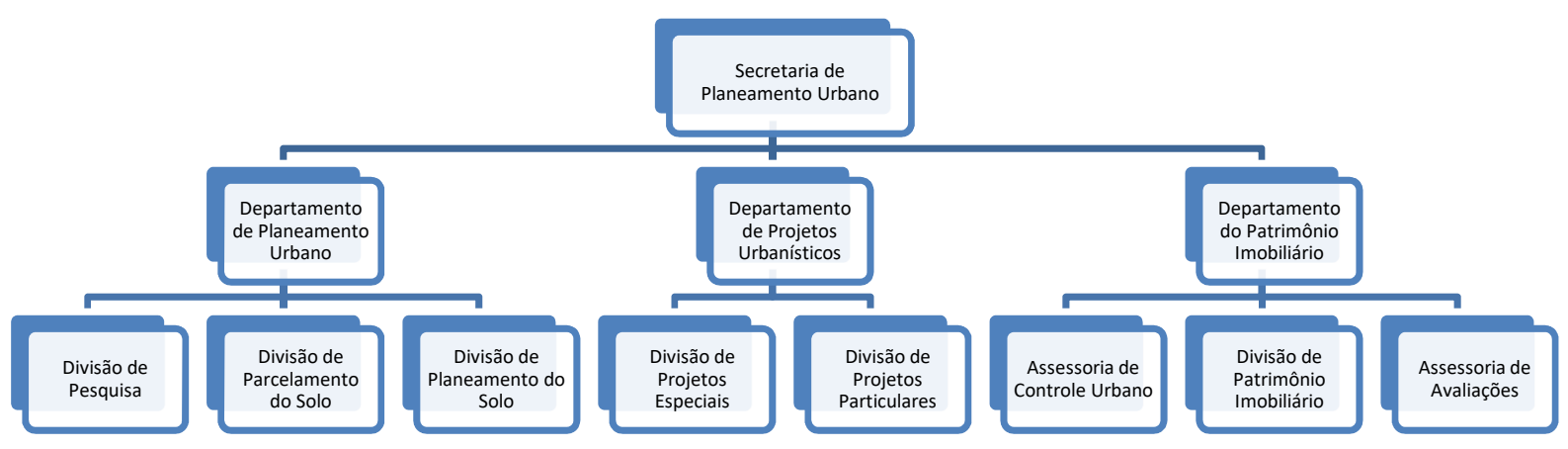

Fig. 1 - Estrutura Orgânica da Secretaria de Planeamento e Meio Ambiente na Prefeitura de S. José dos Campos de acordo com a Lei no 3.939/91, em sua redação original

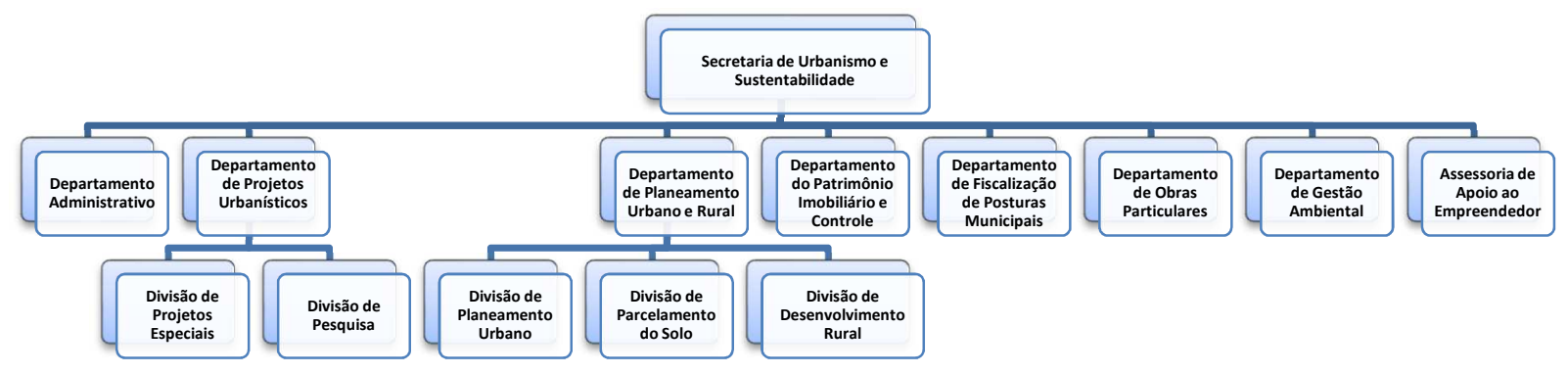

Fig. 2 - Estrutura Orgânica da Secretaria de Planeamento Urbano na Prefeitura de S. José dos Campos de acordo com a Lei no 3.939/91, modificada pelas Leis no 6.808/05 e n 6.880/05.

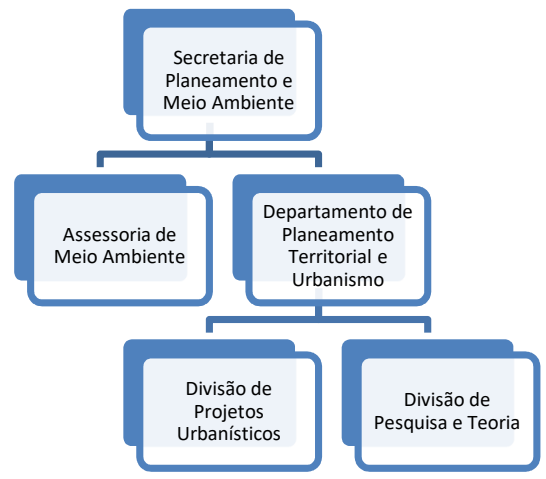

Fig. 3 - Estrutura Orgânica da Secretaria de Urbanismo e Sustentabilidade na Prefeitura de S. José dos Campos de acordo com a Lei no 9.495/2017.

Fonte: Leis no 3.939/91, o 6.808/05, no 6.880/05 e no 9.495/2017. 
O órgão responsável pelos projetos urbanísticos, na redação original da Lei no 3.939/91, estava subordinado ao Departamento de Planeamento Territorial e Urbanismo, sugerindo que a produção e aprovação de projetos urbanísticos, observada a cadeia de poder e o processo decisório, passariam pelo crivo da autoridade responsável pelo Planeamento urbano (Figura 1).

Com as alterações promovidas pelas Leis no 6.880/05 e n $6.808 / 05$, vê-se que a Divisão de Projetos Urbanísticos foi elevada à posição de Departamento, ocupando o mesmo nível hierárquico do órgão responsável pelo Planeamento Urbano (Figura 2).

Na Figura 3, observa-se que o órgão de menor hierarquia, especializado em Planeamento Urbano (Divisão de Planeamento Urbano), encontra-se no mesmo nível do órgão responsável pelos Projetos Especiais (Divisão de Projetos Especiais), sendo tais divisões subordinadas a departamentos diversos, o que revela uma desarticulação entre o Planeamento urbano e a produção do espaço através dos denominados projetos especiais (projetos de requalificação urbana, projetos arquitetónicos e urbanísticos) (SÃO JOSÉ DOS CAMPOS, 2017).

O Quadro 2 possibilita uma visão comparativa entre as atribuições dos dois departamentos situados no mesmo nível hierárquico, conforme previsto na Lei no 9.495/17 (Idem).

\begin{tabular}{|c|c|}
\hline epartamento de Projetos Urbanísticos & Departamento de Planeamento Urbano e Rural \\
\hline $\begin{array}{l}\text { Art. } 32 \text { Ao Departamento de Projetos Urbanísticos } \\
\text { compete estudar, planejar, supervisionar, implantar } \\
\text { e desenvolver e avaliar projetos de requalificação } \\
\text { urbana, projetos de geoprocessamento, da } \\
\text { Administração Municipal, sendo composto pelas } \\
\text { seguintes divisões: } \\
\text { I - Divisão de Projetos Especiais, responsável por } \\
\text { estudar, planejar, supervisionar e desenvolver } \\
\text { projetos de requalificação urbana e projetos } \\
\text { arquitetônicos e urbanísticos da Administração; } \\
\text { II - Divisão de Pesquisa, responsável por elaborar } \\
\text { instrumentos de pesquisas com vista a subsidiar o } \\
\text { diagnóstico e a definição das diretrizes de } \\
\text { desenvolvimento e políticas públicas para o } \\
\text { Município e coletar, organizar e disseminar dados } \\
\text { territoriais, socioeconômicos e cadastrais, com vistas } \\
\text { a subsidiar o desenvolvimento de estudos, projetos } \\
\text { e pesquisas de interesse do Município. }\end{array}$ & $\begin{array}{l}\text { Art. 32-A Ao Departamento de Planeamento Urbano e } \\
\text { Rural compete coordenar, desenvolver, implantar } \\
\text { planos, programas e projetos de Planeamento urbano } \\
\text { e rural e o Plano Diretor de Desenvolvimento Integrado } \\
\text { do Município, sendo composto pelas seguintes } \\
\text { divisões: } \\
\text { I - Divisão de Planeamento Urbano, responsável por } \\
\text { desenvolver, implantar planos, programas e projetos } \\
\text { de Planeamento urbano; } \\
\text { II - Divisão de Parcelamento do Solo, responsável por } \\
\text { analisar, avaliar e aprovar projetos particulares de } \\
\text { loteamentos, desdobros e desmembramentos e } \\
\text { desenvolver o Planeamento viário do Município; } \\
\text { III - Divisão de Desenvolvimento Rural, responsável por } \\
\text { elaborar políticas públicas que fortaleçam o } \\
\text { desenvolvimento local, com geração de renda e } \\
\text { riqueza, cidadania, inovação, conservação ambiental e } \\
\text { qualidade de vida, considerando as oportunidades e } \\
\text { prioridades futuras. }\end{array}$ \\
\hline
\end{tabular}

Quadro 2 - Atribuições dos Departamentos da Secretaria de Urbanismo e Sustentabilidade Fonte: https://leismunicipais.com.br/camara/sp/sao-jose-dos-campos 
Na nova configuração da estrutura orgânica, o órgão responsável pela coordenação, desenvolvimento e implementação do Plano Diretor do Município - instrumento básico da política de desenvolvimento urbano (BRASIL, 1988) - está no mesmo nível hierárquico do órgão responsável pelo desenvolvimento de projetos de requalificação urbana, sinalizando a possibilidade de desarticulação entre projetos urbanísticos e o Plano Diretor.

A aglutinação de diversas funções administrativas, abrangendo áreas do conhecimento das mais variadas e com considerável nível de complexidade (Planeamento Urbano, Meio Ambiente, Posturas Municipais, Patrimônio Imobiliário e Empreendedorismo) em uma única secretaria, sugere um deslocamento no processo de tomada de decisões, para níveis hierárquicos mais baixos, fortalecendo o discurso tecnocrático e a despolitização do processo de Planeamento Urbano.

Ao mesmo tempo, o processo de tomada de decisão sobre projetos considerados estratégicos, incluídos aqueles relacionados ao campo do Planeamento Urbano, foi deslocado para a Assessoria de Assuntos Estratégicos e Avaliação, órgão diretamente subordinado ao Chefe do Executivo, que pode atuar em conjunto ou não, com a Secretaria de Urbanismo e Sustentabilidade (art. 12, I, “c”, da Lei no 9.495/17).

É possível aferir, em síntese preliminar, que o desenho normativo-institucional da Administração Municipal, com as alterações introduzidas pela Lei no 9.495/17, vem sendo moldado para que os órgãos do Estado possam viabilizar um projeto político de viés neoliberal, com inversão lógica do processo de Planeamento, fortalecimento do discurso tecnocrático e consequente despolitização da cidade.

As alterações normativas trazidas pela Lei $n$ ㅇ 9.495/17 coincidem com a recondução ao poder do grupo político que comandou a cidade durante o período de 1997 a 2012, gestão marcada por um discurso da existência de uma "cidade de regras" e "empreendedora", representações sociais que justificam e reforçam o ideário que sustentou a implementação do rearranjo da estrutura orgânica. 


\section{A "cidade das regras" e a "cidade empreendedora" como representações sociais}

O processo de saturação dos grandes centros urbanos no Brasil gerou, entre outras consequências, um acréscimo nos custos de produção, transporte, armazenamento e distribuição das mercadorias, engendrando uma migração das indústrias para o interior do país, onde o custo da mão-de-obra era mais baixo e a existência de uma estrutura já consolidada tornaram-se atrativos determinantes no processo de transferência de plantas industriais.

O fenômeno da migração das indústrias para o interior, verificado com maior intensidade na década de 1970 e fomentado pelo II Plano Nacional de Desenvolvimento, que propugnava grandes investimentos na região sudeste (SOUZA, 1999), encontrou na localização estratégica de São José dos Campos um espaço propício à atração de grande contingente migratório, que vislumbravam uma oportunidade de trabalho, decorrente da implantação de diversas indústrias no município (GOUVEIA \& KURKDJIAN, 2003).

A instalação de grandes indústrias em São José dos Campos, verificada a partir da década de 1940 e incrementada nas décadas subsequentes, proporcionou um crescimento populacional incompatível com a estrutura urbana existente na cidade.

Com a aceleração do processo de industrialização, a imagem de cidade conhecida até então pela sua vocação como estância sanatorial foi sendo substituída pela ideia de cidade dos negócios e das oportunidades, viés destacado até os dias atuais pelo poder público local, ao afirmar que São José dos Campos "é destaque no país devido ao potencial de negócios, fator que impulsiona investimentos na área de hotelaria, comércio e serviços" (PREFEITURA MUNICIPAL DE SÃO JOSÉ DOS CAMPOS, 2017b).

A curva de crescimento demográfico do município demonstra que o número de habitantes em 1950 era de pouco mais de 44 mil pessoas, saltando para 538.909, em 2000, atingindo em 2016, segundo projeção do Instituto Brasileiro de Geografia e Estatística - IBGE, 695.992 habitantes (IBGE, 2017). 
Em 1993, São José dos Campos contava com 736 indústrias, aumentando para 1.659 indústrias em 2011, responsáveis por cerca de 47.500 empregos diretos (PREFEITURA MUNICIPAL DE SÃO JOSÉ DOS CAMPOS, 2014).

A despeito de ser reconhecido como polo tecnológico e de inovação, o município de São José dos Campos seguiu o padrão nacional, apresentando um processo de urbanização com baixos salários, dificultando, desse modo, o acesso à terra e a moradia pela via do mercado imobiliário formal, conforme destaca MARICATO (2003: 153):

"Antes mesmo das chamadas décadas perdidas (anos de 1980 e 1990) a inserção social nas relações capitalistas apresentavam relação complexa entre regra e exceção. Trabalhadores do setor secundário e até mesmo da indústria fordista brasileira foram excluídos do mercado imobiliário privado e, freqüentemente, buscaram a favela como forma de moradia. Trata-se do 'produtivo excluído', resultado da industrialização com baixos salários".

A área urbana do Município de São José dos Campos localiza-se na bacia hidrográfica do Rio Paraíba do Sul, corpo d'água responsável pelo fornecimento de água potável para diversas cidades em três estados brasileiros (São Paulo, Rio de Janeiro e Minas Gerais), incluindo a cidade do Rio de Janeiro, segunda metrópole mais populosa do país.

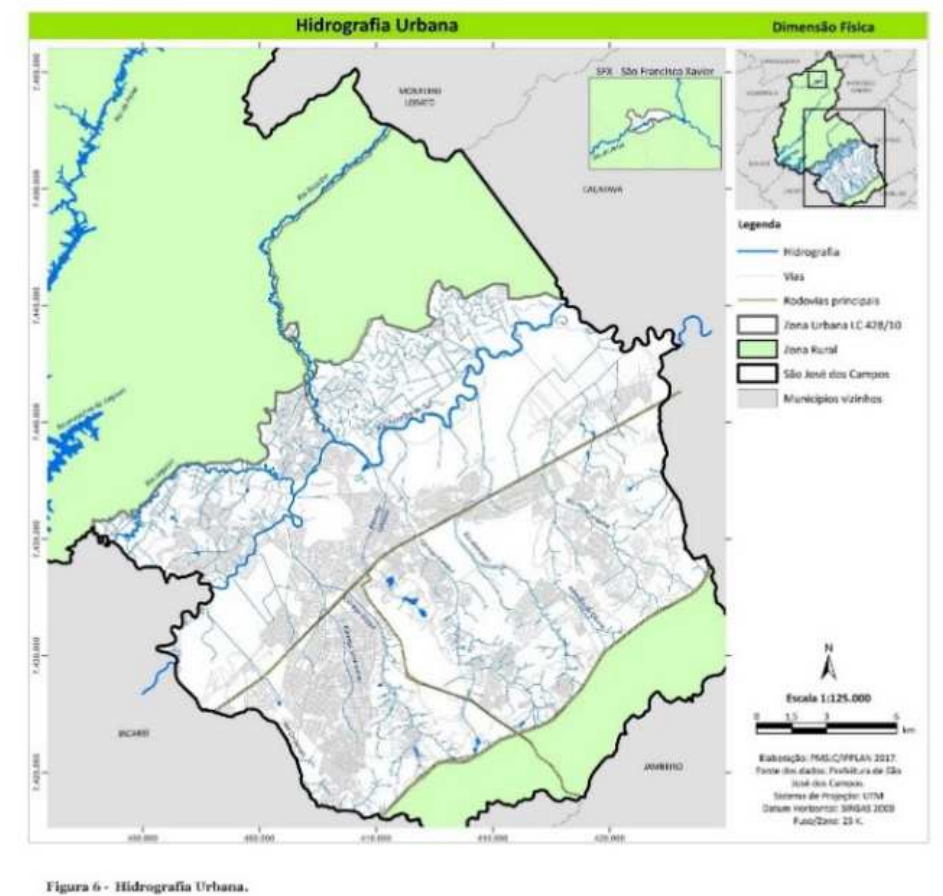

Figura 4 - Hidrologia urbana do Município de São José dos Campos. Fonte: http://planodiretor.sjc.sp.gov.br/mapas-tematicos/2 
A porção norte do município é caracterizada por um relevo com acentuada declividade:

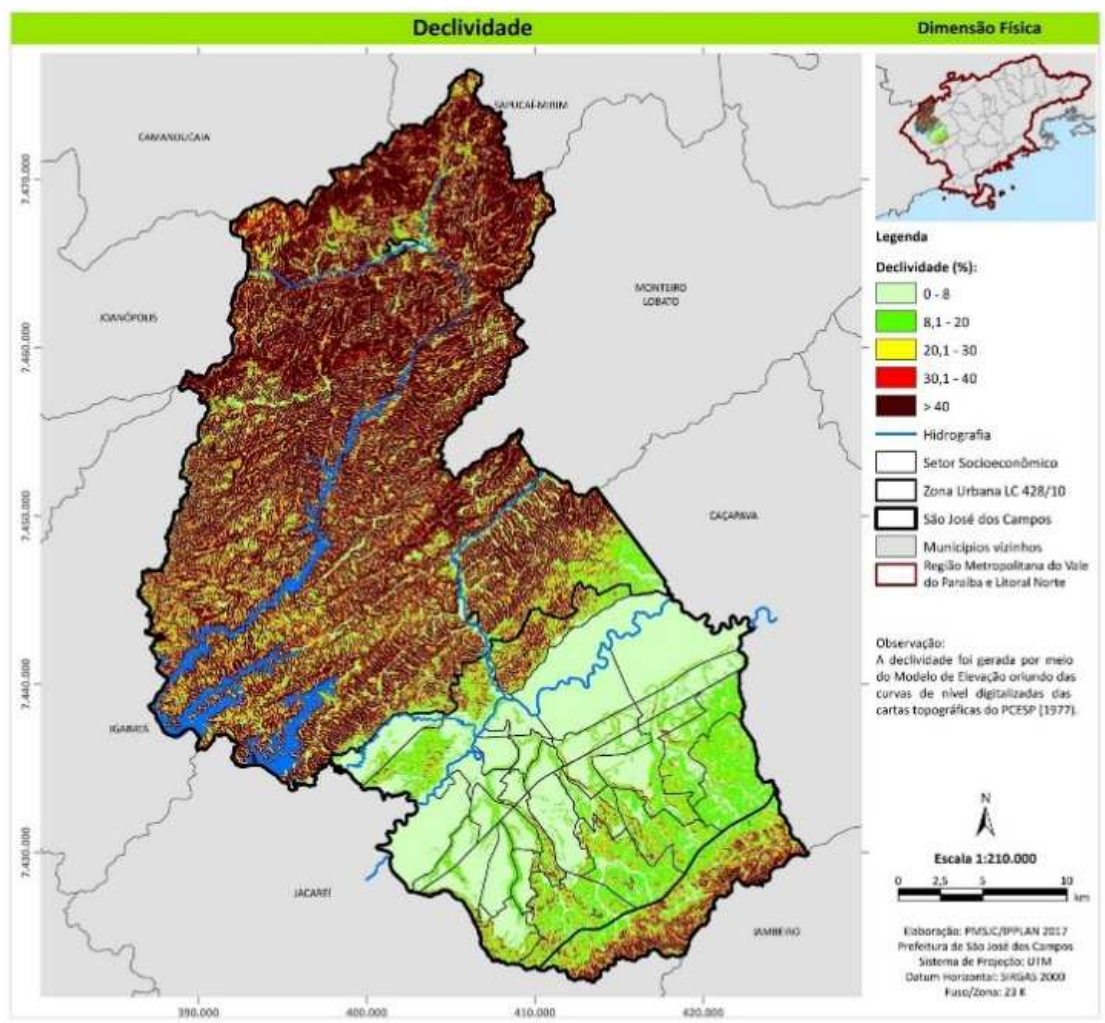

Pigura 3 - Declividade.

Figura 5 - Relevo do Município de São José dos Campos. Fonte:

http://planodiretor.sjc.sp.gov.br/templates/planodiretorsjc/site/images/mapas/figura3.jpg

Além dos obstáculos naturais, limitadores do crescimento físico da cidade, a expansão da ocupação territorial foi limitada ainda: (a) pela implantação do Centro de Tecnologia da Aeronáutica - CTA (atual DCTA), instalação militar que ocupa vasta área da zona Leste da cidade; (b) pela implantação da Refinaria Henrique Lage - REVAP, assentada em uma área de 10 milhões de metros quadrados, destinada originariamente à expansão urbana, cuja planta instalada impede a comunicação entre bairros da Zona Leste da cidade; e (c) pelo traçado das ferrovias que cortam o município. (PREFEITURA MUNICIPAL DE SÃO JOSÉ DOS CAMPOS, 1994:82).

Todos esses fatores contribuíram para formação do quadro de escassez de terras em áreas urbanas dotadas de infraestrutura e localizadas em zonas mais centrais da cidade, o que sobrevalorizou os espaços urbanos ainda existentes nessas zonas, tornando-os proibitivos para as classes populares. 
As consequências não tardaram a aparecer, com a proliferação de ocupações irregulares e habitações qualificadas como "subnormais" na cidade, o que levou à positivação, através do Plano Diretor de 1971 (Lei Municipal no 1.623, de 30/11/1971), de um "Programa de Desfavelamento" (SÃO JOSÉ DOS CAMPOS, 1971).

A política de eliminação física dos adensamentos considerados subnormais, inaugurada pelo Plano Diretor de 1971 e materializada, inicialmente, pela Lei no 2007/78, que previa a "erradicação de favelas, cortiços e outras habitações inadequadas ou de melhorias de emergência visando à assistência a seus moradores e à higienização das áreas ocupadas" (ROSA FILHO, 2002, p, 71), foi retomada com a mudança do grupo político no exercício do poder municipal de São José dos Campos, ocorrida com a eleição de Emanuel Fernandes, em 1996.

A mudança de paradigma observada na condução da política pública de erradicação das moradias tidas por subnormais na cidade de São José dos Campos, nesse período, tornou-se evidente, pois enquanto no governo anterior, conduzido pela Prefeita Angela Guadagnin (1993-1996), a desfavelização centrava-se na urbanização das favelas, no governo do Prefeito Emanuel Fernandes (1997-2004) e, posteriormente, no governo de Eduardo Cury (2005-2012), a desfavelização passou a priorizar o método da eliminação física das construções e o reassentamento da população residente em outro local, geralmente localizado em zona periférica da cidade.

Um forte discurso lastreado na lei e na ordem repercutiu no tratamento das populações que ocupavam áreas não regularizadas.

“Desde que assumi a prefeitura defini esse espírito de cidade das regras. Primeiro, porque eu acredito nisso. Segundo, porque é uma proteção. Se o sujeito vem perguntar, 'porque você não faz isso' eu respondo: 'isso não está na regra'. Administrar a prefeitura é como administrar uma casa. É a mesma coisa" (FERNANDES,2014).

A expressão "cidade das regras" reflete parte do ideário do grupo político que assumiu o controle da cidade, a partir de 1997, e que permaneceu no poder até 2012. A cidade das regras combatia a "cidade sem regras", territórios sem lei, que tinham nas favelas e nos loteamentos clandestinos sua expressão mais evidente. 
Ao mesmo tempo, a ideia de cidade das regras contrapunha-se e diferenciava-se da política pública adotada anteriormente, que, tolerando a existência desses assentamentos, buscava regularizá-los. Tal política pública era, frequentemente, qualificada de populista:

“Não existe almoço grátis. Alguém sempre paga a conta. O governante não deve cair na tentação populista. Isso é uma praga. Populismo parece uma delícia na hora em que se faz, mas o custo disso é tremendo. Não dê nada. Esse dinheiro não te pertence, ele é comum. A vontade de dar, de fazer exceções é muito grande, mas não dê nada. Não faça favores. $\mathrm{Na}$ hora de fazer os políticos gostam, depois é um inferno. A pessoa para quem você faz o favor conta para todo mundo que você fez o favor e você não vai poder fazer o favor para todo mundo. Então, seja escravo das regras e não o "rei" do favor" (FERNANDES, 2014).

O mencionado "espírito" da cidade de regras e a impiedosa luta contra o "favor" e as "exceções" integram um sistema simbólico de representação social, reforçado ainda pelo discurso da "cidade empreendedora" e do empreendedorismo, lastreado na defesa acrítica da meritocracia.

A despeito da inflexão ao regramento sem níveis de favorecimento ou exceção cumpre destacar a tradição patrimonialista da sociedade brasileira (SCHWARTZMAN, 2006) cuja marca é o plano da modernização alternativa que tem como estruturante entre outros elementos a prevalência da racionalidade substantiva em detrimento da racionalidade formal, resultando naquilo que se pode denominar tendência da aplicação arbitrária da lei.

Desse mesmo modo, as regras que valeram para a racionalidade que explica a remoção de favelas no período (1996-2004), não se aplicaram para a aprovação de loteamentos fechados em áreas ambientais do município de São José dos Campos.

A fácil assimilação das ideias representadas pelo discurso do poder local (respeito às regras, competitividade, possibilidade de sucesso e valorização dos sonhos e do esforço próprio) mascaram a realidade dos mecanismos de produção de juridicidade, das profundas desigualdades sociais e da própria existência da luta de classes.

Como assinalado por SILVA (2014:48), "no discurso da classe dominante não há espaço para as contradições, que são inerentes ao próprio sistema capitalista". 
A noção de "regra" constitui objeto de estudo da dogmática jurídica, em especial dos estudos desenvolvidos por Ronald Dworkin (2011) e, posteriormente, por Robert Alexy, sintetizados na sua obra Teoria dos Direitos Fundamentais (2012).

Na conceção de Robert Alexy, princípios e regras seriam duas espécies do gênero "norma", estando ambos relacionados ao "dever-ser" e podendo ser reduzidos aos operadores deônticos básicos do dever, da proibição e da permissão. Segundo ALEXY (2012: 90), princípios seriam "mandamentos de otimização", constituindo-se em "normas que ordenam que algo seja realizado na maior medida possível dentro das possibilidades jurídicas e fáticas existentes".

Assim, os princípios admitiriam a satisfação do enunciado normativo nele expresso em diversos graus, a partir de dois limitadores: as possibilidades fáticas e as possibilidades jurídicas, sendo estas delimitadas pelos conflitos entre princípios e regras colidentes.

As regras seriam espécies de normas de caráter binário, que são sempre satisfeitas ou não satisfeitas, veiculando determinações no âmbito do que é possível fática e juridicamente.

O sentido atribuído por Dworkin às regras se assemelha ao desenvolvido posteriormente por Alexy, diferenciando-se, entretanto, no que tange à conceção segundo a qual regras e princípios seriam espécies do gênero norma. Para Dworkin, princípios e regras não guardariam qualquer relação hierárquica, distinguindo-se pela natureza da orientação que oferecem (2011: 36).

Assim, o caráter binário das ideias propagadas pelo poder local facilita a apreensão simplificada do real, sua ressignificação, produção e reprodução social, impondo seus valores e conceções de mundo (BOURDIEU, 1989: 10-11), naturalizando a implementação de políticas públicas e modificações legislativas, inclusive na estrutura do poder, propensas a viabilizar tal projeto.

O discurso da cidade de regras e empreendedora é de fácil leitura e assimilação, apto a forjar um amplo consenso social em torno de um projeto político que atribui ao indivíduo a responsabilidade por sua própria sorte, tendendo a cingir a sociedade sempre em dois campos distintos (os que respeitam as regras e os desordeiros; os empreendedores e os indolentes etc.), em viés invariavelmente maniqueísta. 
Entretanto, como a realidade social não comporta simplificações, e como a apreensão e ressignificação do discurso oficial não se dá de forma linear e homogênea, sempre surgem contradições entre as práticas empreendedoras e a cidade das regras.

Os casos de vendedores ambulantes que têm suas atividades reprimidas em nome da ordem urbana, ou, ainda, o caso dos parcelamentos irregulares, onde "empreendedores" constroem a cidade a despeito da lei, são exemplos dessa contradição.

A vida fora da "ordem" é, por consequência, muitas vezes, produzida pela própria "ordem" que é estabelecida em diversos níveis (econômico, jurídico, social e político).

\section{O arranjo que gera a "nova" ordem}

A vida "fora da lei" e do Estado Democrático de Direito não constitui sequer opção para parcela considerável da população urbana.

Estudo da Commission on Legal Empowerment of the Poor da Organização das Nações Unidas, divulgado em 2008, já apontava que pelo menos quatro bilhões de pessoas no mundo viviam, naquela oportunidade, "fora da lei": "[...] a maioria das pessoas pobres não vive sob o abrigo da lei, mas bem longe da proteção da lei e das oportunidades que ela oferece. As normas e instituições locais informais governam suas vidas e seus meios de subsistência e, quando não estão excluídas do sistema legal, muitas vezes, são oprimidas por ele. [...] A Comissão considera que pelo menos quatro bilhões de pessoas estão excluídas do Estado de Direito. É a minoria das pessoas do mundo que pode tirar proveito das normas e regulamentos legais. A maioria da humanidade está olhando de fora, incapaz de contar com a proteção da lei e incapaz de entrar em mercados nacionais e, muito menos, mundiais". (UNITED NATIONS DEVELOPMENT PROGRAM, 2008: 2-3). Livre Tradução.

Como assinala SANTOS (2002: 112) "uma boa parcela da humanidade, por desinteresse ou incapacidade, não é mais capaz de obedecer a leis, normas, regras, mandamentos, costumes derivados dessa racionalidade hegemônica. Daí a proliferação de 'ilegais', 'irregulares', 'informais'”. 
Ordem e contraordem, produzidas pela esquizofrenia do espaço e do território (SANTOS, 2002: 114), convivem em permanente conflito, muitas vezes mediados por políticas públicas insuficientes ou ineficazes que atuam somente na mitigação das consequências do passivo deixado pela racionalidade hegemônica conglobante, reflexo direto do modo de produção capitalista em seu estágio atual.

O modelo de desenvolvimento ditado pelo processo de globalização, caracteriza-se pela "estreita interação entre as pressões globalizantes e o modo como as identidades locais são negociadas, modeladas e remodeladas" (BAUMAN, 2009:28).

Nesse contexto de inserção do local na escala global, a alteração do desenho normativoinstitucional da Prefeitura Municipal de São José dos Campos, implementada pela Lei no 9.495/2017, sinaliza a adesão à lógica hegemônica, com a preparação da estrutura orgânica para a retomada de uma agenda neoliberal radical, com impacto na organização do espaço e do território.

Os sinais são claros e apontam para o abandono do Planeamento estrutural, com rebaixamento ao nível operacional e priorização de "projetos estratégicos", geralmente voltados à atração de empresas e investimentos, fomentando a denominada "ordem desordeira" (SANTOS, 2002), ao impor uma lógica voltada aos interesses de alguns atores, ao mesmo tempo em que produz uma desordem para todo o resto.

A análise evolutiva do Planeamento Urbano em São José dos Campos revela a ascensão e derrocada do modelo autoritário-técnico-burocrático, fortalecendo a adesão atual à proposta de Planeamento estratégico, em viés empresarial.

Neste sentido, VAINER (2002: 75) assinala que "entre os modelos de Planejamento urbano que concorrem para ocupar o trono deixado vazio pela derrocada do tradicional padrão tecnocrático-centralizado-autoritário, está o do chamado Planejamento estratégico".

Para VAINER, o nexo central da nova questão urbana estaria na competitividade que significaria "competir pelo investimento de capital, tecnologia e competência gerencial; na atração de novas indústrias e negócios; no preço e na qualidade dos serviços; na atração de força de trabalho adequadamente qualificada" (2002: 76). 
A institucionalização da ideologia (neo)liberal, com vinculação estrutural do empreendedorismo ao órgão teoricamente responsável por pensar a cidade (Secretaria de Urbanismo e Sustentabilidade), milita a favor da construção de uma imagem de "cidade empreendedora", em sintonia com o sustentado por SÁNCHEZ (1999), sobre a estreita relação entre os planos estratégicos (forjadores de consensos) e o marketing da cidade, uma vez que há fabricação de imagem para consumo externo e também para o público interno, buscando uma ampla adesão social ao modelo de gestão e administração empresarial.

As ideias de "cidade das regras" e, especialmente, de "cidade empreendedora" pretendem atribuir uma característica particular (imagens-marca) com valorização da dimensão local no contexto da globalização econômica (SÁNCHEZ, 1999: 115).

Em estudo que se tornou clássico, VAINER (2002) apresenta três analogias associadas ao modelo estratégico-empresarial de Planeamento: cidade-mercadoria, cidade-empresa e cidade-pátria.

Pela analogia da cidade-mercadoria, a cidade seria um bem de consumo a ser vendido livremente no mercado: "Talvez esta seja, hoje, uma das ideias mais populares entre os neoplanejadores urbanos: a cidade é uma mercadoria a ser vendida, num mercado extremamente competitivo, em que outras cidades também estão à venda. Isto explicaria que o chamado marketing urbano se imponha cada vez mais como uma esfera específica e determinante do processo de Planejamento e gestão de cidades. Ao mesmo tempo, aí encontraríamos as bases para entender o comportamento de muitos prefeitos, que mais parecem vendedores ambulantes que dirigentes políticos" (VAINER, 2002:78).

O Planeamento estratégico empresarial ancorado na segunda analogia (cidade-empresa) pressupõe a despolitização do debate em torno da cidade e o afastamento dos controles políticos e burocráticos, em busca da máxima produtividade e competitividade (VAINER, 2002: 90), com reforço à ideia de gerência empresarial, havendo pouco espaço para participação política e para a gestão democrática, e "uma clara confluência de interesses entre o governo da cidade e os setores empresariais" (SÁNCHEZ, 2002:119).

As grandes empresas são transformadas "em entidades políticas com crescente grau de interferência nas políticas do Estado" (SÁNCHEZ, 2002: 119), atuando no nível local, com 
formulação de exigências de construção de arcabouços legislativos que deem segurança jurídica aos seus investimentos.

A terceira analogia suscitada por Vainer é a da cidade-pátria, resultado da necessidade de construção de um consenso que legitime a perda da cidadania.

O mito da cidade-pátria ou do patriotismo de cidade é construído a partir da perceção da crise de crescimento ou de perda de oportunidades (BORJA \& CASTELLS, 1997: 166 apud VAINER, 2002: 93).

O sentimento de crise enseja a construção de um consenso para salvação da cidade, lastreado, muitas vezes, no denominado "urbanismo monumentalista patriótico", assim explicitado por Borja \& Castells (1997: 166):

"Cabe ainda ao governo local a promoção interna à cidade para dotar seus habitantes de 'patriotismo cívico', de sentido de pertencimento, de vontade coletiva de participação e de confiança e crença no futuro da urbe. Esta promoção interna deve apoiar-se em obras e serviços visíveis, tanto os que têm um caráter monumental e simbólico como os dirigidos a melhorar a qualidade dos espaços públicos e o bem-estar da população".

A necessidade de cultivo desse senso cívico pela melhora da autoestima coletiva, a partir de intervenções urbanísticas estratégicas, explica, em certa medida, a ênfase dada na nova estrutura orgânica da Prefeitura de São José dos Campos aos projetos específicos de "requalificação" urbana, cuja elaboração é de responsabilidade do Departamento de Projetos Urbanísticos, setor situado no mesmo nível hierárquico do Departamento de Planeamento Urbano e Rural, responsável, em tese, por desenvolver planos e programas de Planeamento urbano e rural, instrumentos de níveis lógico-hierárquicos superiores.

A criação de um sentimento de pertencimento, sentido cívico e lealdade cumpre ainda uma outra função: camuflar a distribuição não equitativa dos ônus e bônus da reestruturação urbana (SÁNCHEZ, 2002).

Confirmada a tese da esquizofrenia do espaço, sustentada por SANTOS (2002: 114), segundo a qual o território, ao acolher os vetores da globalização, que neles se instalam para impor sua nova ordem", ao mesmo tempo, "neles se produz uma contraordem, porque há uma produção acelerada de pobres, excluídos, marginalizados", a reestruturação orgânica 
promovida pela Lei no 9.495/2017, estaria contribuindo para a inauguração de um novo ciclo de produção de desordem no âmbito local, ainda que levada a cabo sob o signo da cidade empreendedora e das regras.

\section{Conclusão}

Sem afastar o risco de incidir em exacerbada simplificação, conclui-se que a produção jurídica não é neutra e que a arquitetura normativa elaborada sob o signo da eficiência administrativa e lastreada nos mitos da "cidade das regras" e "empreendedora" contribui para perpetuar a lógica hegemônica dos "fatos consumados" que vão legitimar e justificar discurso de reforço à gestão estratégica, com a consequente despolitização da cidade e Planeamento de baixo espectro, reduzido aos níveis operacionais da cadeia hierárquica de poder, tal como efetivado pelo rearranjo da estrutura orgânica implementado pela Lei Municipal no 9.495/2017, de São José dos Campos.

À "cidade de regras" pode-se opor a "cidade de princípios" lastreada na primazia do Planeamento urbano democrático, com a politização da cidade, resgate do conteúdo ético das normas jurídicas e fomento às resistências e à (re)construção de utopias.

À "cidade empreendedora" pode-se opor a "cidade solidária", derivada de uma nova ética urbana, lastreada no Direito à Cidade, com fundamentos na justiça social e na cidadania e com a prevalência dos direitos urbanos, através de seus instrumentos, de forma a viabilizar as transformações necessárias para que a cidade exerça a sua função social (PLATAFORMA DHESCA BRASIL 2010).

\section{Referências bibliográficas}

ALEXY, Robert. Teoria dos Direitos Fundamentais. 2.ed. São Paulo: Malheiros, 2012. ISBN 85-392-0073.

BARROSO, Luís Roberto. Interpretação e Aplicação da Constituição: Fundamentos de uma Dogmática Transformadora. 5. Ed. São Paulo: Saraiva, 2003. ISBN: 978-85-020-3541-6.

BAUMAN, Zygmunt. Confiança e medo na cidade. Rio de Janeiro: Zahar, 2009. ISBN: 978-85-378-0122-2. 
BOBBIO, Norberto. Dicionário de política. Vol. I; 11.ed. trad. Carmen C, Varriale et al.. Brasília : Editora Universidade de Brasília, 1998. ISBN 978-85-852-3003-0.

BOBBIO, Norberto. Teoria do Ordenamento Jurídico. 9. ed. Brasília: Universidade de Brasília, 1997. ISBN 97885-7283-751-4.

BOURDIEU, Pierre. O Poder Simbólico. Rio de Janeiro, Bertrand Brasil, 1989. ISBN 972-29-0014-5

BRASIL. Constituição (1988). Constituição da República Federativa do Brasil. In: PELUSO, Antonio Cezar. As constituições do Brasil: 1824, 1891, 1934, 1937, 1946, 1967 e 1988. Barueri: Manole, 2011. ISBN 978-85-2043303-4.

COSTA, Paulo Eduardo Oliveira. Legislação urbanística e crescimento urbano em São José dos Campos. 2007. 257f. Dissertação de Mestrado - Faculdade de Arquitetura e Urbanismo, Universidade de São Paulo, São Paulo, 2007.

DWORKIN, Ronald. Levando os direitos a sério. São Paulo: Martins Fontes, 2011. ISBN 978-85-7827-251-7.

FERNANDES, Emanuel. Público X Privado. Disponível em: http://emanuelfernandes.com.br/site/?page_id=92 acesso: 20/09/2014, às $21 \mathrm{~h}: 30 \mathrm{~m}$

GOUVEIA, Rosana Aparecida Ravanelli \& KURKDJIAN, Maria de Lourdes N.O. O espaço urbano e a clandestinidade: um estudo de caso dos loteamentos clandestinos no município de São José dos Campos - SP. $X$ Encontro Nacional da ANPUR, Belo Horizonte: ANPUR, 2003. Em CD.

HERRERA-FLORES, Joaquin. Hacia una visión compleja de los derechos humanos. En El vuelo de Anteo. Derechos humanos y crítica de la razón liberal. Bilbao: Desclée de Brouwer, S.A., 2000. ISBN 978-84-3301-5419.

IBGE. Cidades. São José dos Campos. 2017. Disponível em: https://cidades.ibge.gov.br/v4/brasil/sp/sao-josedos-campos/panorama. Acesso em 15 jun 2017.

MARICATO, Ermínia. Brasil 2000: qual planejamento urbano? Cadernos IPPUR, v. XI, números 1 e 2, jan-dez, 1997. pp 113-130.

MARICATO, Ermínia.Metrópole, Legislação e Desigualdade. São Paulo: Estudos Avançados, 2003, Pp-151-167.

ISSN 1806-9592

PLATAFORMA DHESCA BRASIL. Coleção Cartilhas de Direitos Humanos - V. 6. Direito Humano à Cidade. Paraná: DHESCA, 2010.

PREFEITURA MUNICIPAL DE SÃO JOSÉ DOS CAMPOS. A harmonia entre cultura, tradição e tecnologia. 2017. Disponível em: http://www.sjc.sp.gov.br/sao_jose.aspx. Acesso em 15 de junho de 2017, às 22h:31min.

PREFEITURA MUNICIPAL DE SÃO JOSÉ DOS CAMPOS. Caderno técnico do Plano Diretor de Desenvolvimento Integrado - PDDI, 1994.

PREFEITURA MUNICIPAL DE SÃO JOSÉ DOS CAMPOS. São José tem Matriz Curricular e novo Plano de Educação. Disponível em: http://www.sjc.sp.gov.br/noticias/noticia.aspx?noticia_id=12824. 12 dez. 2012. Acesso em: 15 jun 2017.

PREFEITURA MUNICIPAL DE SÃO JOSÉ DOS CAMPOS. Complexo industrial. 2014. Disponível em: http://www.sjc.sp.gov.br/negocios/complexoindustrial.aspx, acesso em 27/09/2014, às 18h46min.

PREFEITURA MUNICIPAL DE SÃO JOSÉ DOS CAMPOS. Empreendedorismo. 2017b, Disponível em: http://www.sjc.sp.gov.br/secretarias/educacao_cidadania/empreendedorismo.aspx. Acesso em 21 de maio de 2017, às $11 \mathrm{~h}: 42 \mathrm{~min}$

ROSA FILHO, Artur. As políticas públicas do poder executivo na remoção e/ou reurbanização de favelas o município de São José dos Campos - SP. Dissertação de Mestrado, UNIVAP, 2002.

SÁNCHEZ, Fernanda. Políticas Urbanas em Renovação. Revista Estudos Urbanos e Regionais, no 1, maio, 1999. Pp. 115-132, ISSN 1517-4115.

SANTOS, Milton. Por uma outra globalização. Rio de Janeiro: Record, 2002. ISBN 978-85-0105-878-5. 
SÃO JOSÉ DOS CAMPOS. Lei no 1.533, de 06 de janeiro de 1970. Fixa a organização administrativa da Prefeitura da Estância de São José dos Campos e dá outras providências. Jornal do Município. n. 37. São José dos Campos, 10 jan. 1970.

SÃO JOSÉ DOS CAMPOS. Lei no 1.534, de 06 de janeiro de 1970. Cria a Assessoria de Coordenação e Planeamento Municipal - ACEPLAM. Jornal do Município. n. 37. São José dos Campos, 10 jan. 1970 b.

SÃO JOSÉ DOS CAMPOS. Lei no 1.537, de 03 de março de 1970. Dispõe sobre a organização administrativa da Prefeitura da Estância de São José dos Campos e dá outras providências. Jornal do Município. n. 41. São José dos Campos, 12 mar. 1970c.

SÃO JOSÉ DOS CAMPOS. Lei no 1.788, de 23 de abril de 1976. Dispõe sobre a organização administrativa da Prefeitura Municipal. Boletim do Município. n. 173. São José dos Campos, 30 abr. 1976.

SÃO JOSÉ DOS CAMPOS. Lei no 2.151, de 22 de março de 1979. Estabelece a nova organização administrativa da Prefeitura Municipal e dá outras providências. Boletim do Município. n. 219. São José dos Campos, 24 mai. 1979.

SÃO JOSÉ DOS CAMPOS. Lei no 2.325, de 19 de setembro de 1980. Estabelece a Organização Administrativa da Prefeitura Municipal de São José dos Campos, e dá outras providências. Boletim do Município. n. 248. São José dos Campos, 23 set. 1980.

SÃO JOSÉ DOS CAMPOS. Lei no 2.499, de 01 de setembro de 1981. Dispõe sobre alterações nas Leis no 2325/80 e no 2427/81, e dá outras providências. Boletim do Município. n. 288. São José dos Campos, 03 set. 1981.

SÃO JOSÉ DOS CAMPOS. Lei no 3.155, de 11 de agosto de 1986. Dispõe sobre a reorganização administrativa da Prefeitura Municipal de São José dos Campos e dá outras providências. Boletim do Município. n. 510. São José dos Campos, 11 ago. 1986.

SÃO JOSÉ DOS CAMPOS. Lei no 3.939, de 21 de março de 1991. Dispõe sobre a estrutura administrativa da Prefeitura Municipal de São José dos Campos. Boletim do Município. n. 784. São José dos Campos, 22 mar. 1991.

SÃO JOSÉ DOS CAMPOS. Lei no 6.808, de 25 de maio de 2005. Cria a Secretaria de Habitação e a Secretaria de Meio Ambiente, destinadas a planejar e executar, respetivamente as políticas habitacional e do meio ambiente do Município, dá outras providências. Boletim do Município. n. 1671. São José dos Campos, 31 mai. 2005.

SÃO JOSÉ DOS CAMPOS. Lei no 6.880, de 20 de setembro de 2005. Reestrutura a Secretaria de Obras e a Secretaria de Planejamento Urbano, e dá outras providências. Boletim do Município. n. 1690. São José dos Campos, 23 set. 2005.

SÃO JOSÉ DOS CAMPOS. Lei no 7.823, de 03 de abril de 2009. Reestrutura o Gabinete do Prefeito e dá outras providências. Boletim do Município. n. 1891. São José dos Campos, 03 set. 2009.

SÃO JOSÉ DOS CAMPOS. Lei no 9.495, de 24 de março de 2017. Altera a Lei n. 3.939, de 21 de março de 1991 , que "Dispõe sobre a Estrutura Administrativa da Prefeitura Municipal de São José dos Campos.". Boletim do Município. n. 2377. São José dos Campos, 17 fev. 2017.

SÃO JOSÉ DOS CAMPOS. Lei no 1.623, de 30 de novembro 1971. Institui o Plano Diretor de Desenvolvimento Integrado do Município de São José dos Campos, e dá outras providências. Boletim do Município. n. 80. São José dos Campos, 08 dez. 1971.

SCHWARTZMAN Simon. Nota sobre o patrimonialismo e a dimensão pública na formação da América Latina contemporânea, 2006. Disponível em: http://www.schwartzman.org.br/simon/patrimonialismo06.pdf.

SILVA, Márcia da. Poder local, ideologia e representações sociais. Mercator (Fortaleza) [online]. 2014, vol.13, n.2, pp.39-51. Disponível em: <http://www.scielo.br/scielo.php?script=sci_arttext\&pid=S198422012014000200039\&Ing=en\&nrm=iso>. ISSN 1984-2201. http://dx.doi.org/10.4215/RM2014.1302.0003. SOUZA, Maria Adélia Aparecida de. O II PND e a política urbana brasileira: uma contradição evidente. In: O processo de urbanização no Brasil [S.I: s.n.], 1999.

ULTRAMARI, Clóvis. Significados do urbanismo. Pós. Revista do Programa de Pós-Graduação em Arquitetura e Urbanismo da FAUUSP, São Paulo, n. 25, p. 166-184, junho 2009. ISSN 2317-2762. Disponível em: 
<http://www.revistas.usp.br/posfau/article/view/43614>.

Acesso

em:

15

jun

2017. doi:http://dx.doi.org/10.11606/issn.2317-2762.v0i25p166-184.

UNITED NATIONS DEVELOPMENT PROGRAM (UNDP). Commission on Legal Empowerment of the Poor and United Nations Development Program (UNDP). Making the Law for Everyone - Report of the Commission on Legal Empowerment of the Poor, Nova York, v. 1, 2008.

VAINER, Carlos. Pátria, Empresa e Mercadoria. Notas sobre a estratégia discursiva do Planeamento estratégico urbano in: ARANTES, Otília, VAINER, Carlos \& MARICATO, Ermínia. A cidade do pensamento único. 3.ed. São Paulo: Vozes, pp. 75-103, 2002. ISBN 978-85-3262-384-3.

WOLKMER, Antonio Carlos. Ideologia, estado e direito. São Paulo: Revista dos Tribunais, 1989. ISBN 85-2032420-7. 